\title{
Corela
}

Cognition, représentation, langage

17-2 | 2019

Vol. 17, $\mathrm{n}^{\circ} 2$

\section{Excuse me vs. (I'm) sorry as two contrasting markers of interlocutive relations}

Hélène Margerie and Philippe Muller

\section{(2) OpenEdition}

1 Journals

\section{Electronic version}

URL: http://journals.openedition.org/corela/9711

DOI: 10.4000/corela.9711

ISSN: 1638-573X

\section{Publisher}

Cercle linguistique du Centre et de I'Ouest - CerLICO

\section{Electronic reference}

Hélène Margerie and Philippe Muller, "Excuse me vs. (I'm) sorry as two contrasting markers of interlocutive relations", Corela [Online], 17-2 | 2019, Online since 21 January 2021, connection on 21 January 2021. URL: http://journals.openedition.org/corela/9711 ; DOI: https://doi.org/10.4000/corela. 9711

This text was automatically generated on 21 January 2021.

\section{(i) (3)}

Corela - cognition, représentation, langage est mis à disposition selon les termes de la licence Creative Commons Attribution - Pas d'Utilisation Commerciale - Partage dans les Mêmes Conditions 4.0 International. 


\section{Excuse me vs. (I'm) sorry as two contrasting markers of interlocutive relations}

Hélène Margerie and Philippe Muller

We are grateful to the two reviewers of this paper for their helpful comments and suggestions.

\section{Introduction}

1 This article is an attempt to re-examine the meaning of excuse me and (I'm) sorry usually considered as two "common formats for apologizing" in English (Fatigante and al., 2015: 27; see also Trosborg, 1987: 152; Meier, 1996: 216; Ogiermann, 2009: 103, 105). In the literature, much attention has been given to (I'm) sorry, especially in recent work adopting an interactional perspective (Mattson Bean and Johnstone, 1994; Robinson, 2004; Rhys, 2013; Page, 2014; Fatigante and al., 2015; Galatolo and al., 2015; Margutti and al., 2016). By contrast, less research has been conducted on excuse me, and since Borkin and Reinhart (1978), there has been - to our knowledge - no attempt at (re)defining (I'm) sorry in the light of excuse me (or vice versa), at least on a synchronic level (for a diachronic perspective, see Jucker and Taavitsainen, 2008; Taavitsainen and Jucker, 2008).

2 It is Borkin and Reinhart's (1978) comparative method that the present paper tries to renew. Borkin and Reihnart's contrastive definitions of excuse me and (I'm) sorry relied mostly on apologetic contexts of use. More recently, interactional studies have addressed the nonapologetic function of (I'm) sorry. Mattson Bean and Johnstone (1994) and Page (2014), for instance, deal with pragmatic uses of ( $\left.I^{\prime} m\right)$ sorry ${ }^{1}$ in specific situations, i.e. in the workplace and in company-customer interactions through the social media site Twitter, respectively. Our purpose in this paper is to conduct a comparative analysis of excuse me and (I'm) sorry in various (mostly nonapologetic) environments, and to provide new tentative definitions for both markers, which are not considered here as apology markers per se. We think these new (hypothetical) 
definitions might account for why they sometimes appear to be mutually exclusive or at least hardly interchangeable, and also explain their sequential order when used jointly.

3 This paper also differs from previous studies on excuse me and/or (I'm sorry) in that we adopt a systematic contrastive approach. Within the framework of Douay and Roulland's (2014) Théorie de la Relation Interlocutive ("Theory of Interlocutive Relation", henceforth TIR), we propose that every contextual interpretation of excuse me and (I'm) sorry systematically derives from the fact that they fundamentally mark two different types of 'interlocutive relations'. As we will make clear in Section 3, this phrase does not refer to the type of discursive relation that emerges as interaction proceeds between two pre-existing extra-linguistic subjectivities, but rather to a relation that has systematic roots and concerns the two theoretical profiles - sender and recipient which necessarily emerge within the communication process. These are introduced to capture the idea that linguistic signs are, from the start, encoded in relation to a more or less hypothetical conversation partner and they do not necessarily correspond to any real-world entities, although they can be interpreted as such further down the line.

Our hypothesis is that both excuse me and (I'm) sorry are meant to communicate two different types of sender/recipient relations to the receiving end of the message. We propose that the former expression is fundamentally a form of discordance between sender and recipient which contrasts with (I'm) sorry, which we analyse as a systematic form of harmony between the two poles involved in the communication process (see Section 6).

5 The paper is organised as follows. We start out in Section 2 by providing some background to the study of apologies, especially focusing on previous work on the different pragmatic functions of excuse me and (I'm) sorry and their interactional function(s) in specific social situations. In Section 3, we lay out the main assumptions put forward within the TIR framework which distinguish it from the field of pragmatics in general and account for the reason why we consider our study to be a new contribution to the study of excuse me and (I'm) sorry as (so-called) 'apology' forms. In Section 4, we provide methodological detail and point to the limitations of the contrastive study that is conducted in Sections 5 to 7 between excuse me and (I'm) sorry. More particularly, we will discuss possible exclusive contexts of use of the two forms in Section 5, which will lead us to delineate some aspects of what we assume to be their linguistic identity. In Section 6, we proceed to examine situations in which they might possibly be considered interchangeable, but will however argue that this is not exactly the case and assume that the inappropriateness of either excuse me or (I'm) sorry in these contexts is related to the type of interlocutive relation that each is supposed to encode. Section 7 elaborates on this hypothesis by providing examples of joint occurrences of the two markers in which the order of the sequence $<$ (I'm) sorry, excuse me> vs. <excuse me, (I'm) sorry> is seen to be crucial. Section 8 offers some final conclusions.

\section{Relevant literature}

6 Over the past four decades, apologising has been a popular subject in linguistics, particularly in pragmatics. It has been studied extensively both synchronically (Borkin and Reinhart, 1978; Fraser, 1981; Trosborg, 1987, 1995; García, 1989; Mattson Bean and 
Johnstone, 1994; Aijmer, 1996; Deutschmann, 2003; Robinson, 2004; Page, 2014; Fatigante and al., 2016; Galatolo and al., 2016; Lutzky and Kehoe, 2016) and diachronically (Jucker and Taavitsainen, 2008; Taavitsainen and Jucker, 2008; Drew and al., 2016; Kohnen, 2017; Jucker, 2018). Some of the main topics addressed in previous work are the characteristics of apologies as a speech act (e.g. Blum-Kulka and al., 1989), the form and function of remedial expressions (Edmonson, 1981; Fraser, 1981; Aijmer, 1996), and the role of social variables such as age, gender, social distance or power in the use of different forms of apology (Deutschmann, 2003). There have also been a large number of studies offering a cross-cultural approach to the subject (Blum-Kulka and Olhstain, 1984; Blum-Kulka and al., 1989; García, 1989; Meier, 1992; Bamgbose, 1994; Tanaka and al., 2008; Ogiermann, 2009). Of particular interest for the present paper are interaction-based studies which examine the discursive functions of apology forms in apologetic or nonapologetic contexts (Mattson Bean and Johnstone, 1994; Robinson, 2004; Page, 2014; Fatigante and al., 2016).

7 In English, apologising relies essentially on a small repertoire of routinised, formulaic expressions such as (be) sorry, pardon, excuse, apologise, regret or (be) afraid (Blum-Kulka and al., 1989: 290; Aijmer, 1996: 86). Previous research has been conducted on the distinctions between the two routinised formulae under scrutiny in this article, i.e. excuse me and (I'm) sorry, either from a synchronic (Borkin and Reinhart, 1978) or a diachronic perspective (Jucker and Taavitsainen, 2008; Taavitsainen and Jucker, 2008). Borkin and Reinhart (1978: 57) define excuse me as "a formula to remedy a past or immediately forthcoming breach of etiquette or other minor offense on the part of the speaker". On the other hand, they consider that I'm sorry is not necessarily used as a remedy (Borkin and Reinhart, 1978: 60) and define it as "an expression of dismay or regret at an unpleasantness suffered by the speaker and/or the addressee" (see also Ogiermann, 2009). Trosborg (1987: 152) also categorises I'm sorry as an expression of regret while excuse $m e$ is said to express request for forgiveness. ${ }^{2}$

8 Taavitsainen and Jucker (2008: 8) observe that among the routinised expressions of remorse and regret used to apologise in Modern English, (I'm) sorry "focuses on the speaker's emotion", contrasting with excuse me "which asks for the addressee's forgiveness" (2008: 8). They point out a diachronic change of orientation from addressee-centred apologies to speaker-centred apologies. In the Renaissance, "apologizers asked their addressees to show generosity and forgive or overlook the perpetrated offense. Present-day speakers [...] apologize by expressing their own remorse without presuming or requesting any change of attitude on the part of the addressee" (Taavitsainen and Jucker, 2008: 16; see also Jucker and Taavitsainen, 2008: 241-242). Jucker's (2018) study of the development of apologies in the Corpus of Historical American English (1810-2009) shows that the frequency of sorry has multiplied almost six-fold in the most recent period, leading to the observation that "what used to be sincere requests for exoneration has in many cases turned to token displays of regret".

Mattson Bean and Johnstone (1994) take a completely different view. Focusing on the uses of sorry, excuse and pardon (and their variants) in 62 telephone interviews conducted for a public polling service, they find that very few of the apologies expressed in these interviews - most of which through the use of sorry - are responses to particular personal offences, meant to express regret. On the basis of the observation that "the felicity conditions for apologizing may be met only loosely" in their telephone interviews (Mattson Bean and Johnstone, 1994: 62), they conceive of apologies as falling 
along a continuum, ranging from the most routinised apologies at one end to the most personal and heartfelt at the other. The former, which are for the most part sorry-based apologies, are called "situational" apologies. They "signal and remedy minor interactional difficulties and establish cooperative rapport" with the effect that they ensure the smooth management of the conversation. Their function is "to restore social equilibrium rather than to express genuine regret" (Mattson Bean and Johnstone, 1994: 59). In quite a similar vein, Page (2014) examines the way saying 'sorry' is meant to reestablish rapport between costumers and companies interacting through the microblogging site Twitter.

10 Fatigante and al. (2016) are concerned with the distinctive uses of sorry and I'm sorry. After pointing out that these two sorry-formats "appear to perform analogous actions in several environments, such as in the context of repair; as pre-facing apologies to (virtual) offenses; and as post-facing apologies to offenses" (Fatigante and al., 2016: 27), the authors argue that sorry is more preferably used "as a resource orienting toward progressivity of and closing the apologetic encounter" or as "a ready-made resource serving the preference for continuation and coherence in conversation" when used in nonapologetic environments (Fatigante and al., 2016: 45; see also Rhys, 2013). On the contrary, they consider I'm sorry a more suitable formula in apologetic-dedicated environments, "initiat[ing] an apology when there is subsequently an expansion of the often quite extended apology sequence (Fatigante and al., 2016: 34).

11 We consider the findings of these interactional studies valuable for our comparative analysis of excuse me and (I'm) sorry. We agree that these two forms occur frequently in nonapologetic situations in which they are not responses to particular personal offences, meant to express regret. We wish to use the TIR framework to discuss the idea that (I'm) sorry establishes cooperative rapport between interactants in various situations. Moreover, we think that Fatigante and al.'s (2015) analysis of sorry in terms of "continuation", "progressivity" and "closure" can be extended to I'm sorry when contrasting it with excuse me, provided these terms refer to an absence of interlocutive disruption. Indeed, we will assume in Section 6 that (I'm) sorry systematically establishes a harmonious interlocutive relation between sender and recipient, which contrasts with the hypothesised discordant interlocutive relation marked by excuse me. By 'systematically' we mean that the kind of interlocutive relation just mentioned does not emerge as interaction proceeds, but rather is embedded within the linguistic system. This is where we depart from interactional studies of forms like (I'm) sorry (see Section 3 for more detail).

\section{The Theory of Interlocutive Relation}

\subsection{Background and basic principles}

12 The approach developed in Douay and Roulland's Théorie de la Relation Interlocutive (2014) stems from a critical reading of pragmatic theories which they consider to be essentially "monological" in nature in that they almost always recognise only one communication partner - the speaker - and one side of the communication process emission - as founding principles of linguistic systems. The other partner - the hearer is often treated as a mere "alter ego", which is only introduced further down the line as the entity that is required to process the meaning of the message (Douay, 2005: 5). ${ }^{3}$ In 
the wake of Grice (1975) and subsequent theorising (Horn, 1984; Sperber and Wilson, 1986; Levinson, 2000), traditional pragmatics is "viewed as a form of intention recognition that involves inferentially reconstructing the meaning that the speaker had in mind and wanted to convey, beyond the literal meaning of an utterance" (Papafragou, 2018: 167). When, and if, meaning somehow eventually comes to be shared through communication, it is thanks to contextual "pragmatic exploitations" that build upon local, contextually-dependent and hearer-centred factors. Even though hearerparticipation is taken into account, early approaches to pragmatics do not allow the hearer to play an important role in the original wording nor do they often give the speaker a central role in the construction of meaning. ${ }^{4}$

While criticising early approaches to pragmatics for not paying enough attention to "the ways in which interactional requirements and contingencies impinge upon grammar" (Douay, 2001: 89, Douay and Roulland, 2014) do admit that "duological" views, that is to say more hearer-inclusive ways of understanding linguistic meaning, have been gaining ground ${ }^{5}$ (cf. Benveniste, 1966, 1974; Culioli, 1990 for Enunciative Linguistics; Nølke, 2006, among others, for the Polyphony Theory; Goodwin, 1981; Ford, 1993; Ford and Wagner, 1996; Ochs, Schegloff and Thompson, 1996; Couper-Kuhlen and Selting, 2004, etc., for Interactional Pragmatics). Yet, Douay and Roulland (2014: 20-40) depart from these "duological" theories in that they over-emphasise speakercenteredness (e.g. Enunciative Linguistics) or do not systematically use the receiving end of communication as one of the two organising parameters from which, they claim, every linguistic sign acquires its raison d'être. Both the TIR and interactional linguistics, for instance, are opposed to a Gricean intention-based view of communication. For interactional linguistics, this view is indeed inconsistent with a social constructionist or interactional perspective on communication as a joint and collaborative activity" (Haugh, 2007: 7). In the words of Arundale (2006: 196, quoting Kripendorff, 1984; see also Arundale, 1999, 2008, 2010):

Encoding/decoding models explain communication simply as an output of one system that serves as an input to a separate, independent system. These monologic accounts treat talk between people entirely as a summative phenomenon. In contrast, interactional achievement models take the dyad as the minimum unit of analysis, and explain communication as the conjoint outcome of a single twoperson system.

14 Even though they agree that no aspect of meaning is ever given but should rather be seen as worked out through "interactive negotiations" (2014: 19), Douay and Roulland (2014), however, find it regretful that these interactions, which underline the coconstructed nature of talk (Grainger and Harris, 2003: 3; Mills, 2003: 28, 58; CouperKuhlen and Selting, 2004: 1-5; Arundale, 2006: 208-209; Arundale, 2009: 2080-2085; Mills, 2011: 42; etc.), should be located at a discursive level in interactional frameworks, and not at an anterior stage, i.e. at the systematic level of language.

This is why the TIR relies on the fundamental assumption that the sending and the receiving ends of the message are both equally encoded, system-organising parameters of language (Douay, 2005: 5). In other words, linguistic systems must be designed in such a way that they allow for the very possibility of a meaning that is shareable from the start. As Douay (2001: 80) puts it, the TIR constitutes a non-referential approach building on Gardiner's (1932) study of the "impact of the communicative process on the internal organisation of grammar". Douay and Roulland (2014) call for a shift in perspective to include the construction of "mutual understanding" in linguistic theory. 
Insisting that the primary function of language lies in communication and clearly rejecting the widespread views that it serves to encode the speaker's thought, the TIR is not concerned with messaging but rather tries to show that one must always infer the meaning of grammatical - and, as we would like to demonstrate here, lexical items -, not in reference to any extralinguistic objects or beings - real-world hearers and speakers - but on the basis of a linguistically internalised image of the communication process itself.

We intend to show in Sections 5 to 7 that (I'm) sorry and excuse me form a contrasting pair (a micro-system) that is best-described in terms of what we think is the core function of language: communication. Thus, we shall argue that it is fruitful to consider interaction as an integral part of the descriptive apparatus which is needed to tackle the linguistic identity of (I'm) sorry and excuse me, rather than introduce it on a separate, pragmatic level.

\subsection{Replication}

17 Following the TIR, we believe that the definition of linguistic meaning should include the potentiality of being, or becoming, common to speaker and hearer, and the claim that "shareability" is its most important defining feature explains why this is a central issue within this framework. Douay and Roulland (2014: 161) deal with it through their concept of "replication", which is introduced in an attempt to capture the idea that meaning can only be understood as something which comes to exist "on two sites". The TIR draws from general systems theory and brings together two potentially conflicting principles:

(i) Linguistic signs are signifiers in that they symbolise a sign/meaning association which must allow for common interpretation and a certain level of consensus to become understandable.

(ii) Language is considered on both a general and a local level of organisation. It is treated as a "system of systems", which comprises a set of individual linguistic subsystems.

These principles do not necessarily sit well together since, in accordance with Systems Theory, systems (and subsystems) are "self-organised", which means that they are theoretically autonomous, independent and cannot rely on any external element for their organisation (Douay and Roulland, 2014: 89-102). Therefore, if one accepts that feelings and thoughts are of a different nature to the language system itself, linguistic signs should not be seen as freighters containing semantic information or conveying extra-systemic cognitive states or perceptions about the world, as this would undermine the proposed autonomy of the system. It follows that meaning never "travels", and mutual understanding cannot be assumed to exist independently from communication as it is understood within the TIR framework. Furthermore, although there is no such thing as a completely closed system, reconciling (i) and (ii) both highlights the systemic boundaries that exist between individual - i.e. independent and self-contained - versions of the language and accounts for their need to communicate, while questioning their ability to do so. That is why we shall posit that neither (I'm) sorry nor excuse me contain or encode any direct reference to any offensive event or emotion per se but rather guide linguistically towards two contrasting interpretations of a (potentially offensive) extra-linguistic situation. Replication is a way to highlight the 
need for anticipatory regulation when it comes to interpreting linguistic signs, so that communication can actually take place.

Indeed, on a local level, individual speakers of the language use their own version of the language, so that (i) the meaning that any given speaker associates with a linguistic item is relativistic by nature, i.e. it is only fully valid and operational within the limits of the speaker's subsystem itself, and (ii) it is therefore speculative or "opaque" when considered from the outside, i.e. from within another individual subsystem. Thus, any linguistic sign necessarily enjoys inferential, rather than referential meaning when considered by another speaker (Douay and Roulland, 2014: 138). Considered on a local, rather than a universal level, each sign/meaning association is "a private affair" (Douay and Roulland, 2014: 50). The above assumptions entail that all the speaker can do is anticipate what we wish to call the "replicability" of the sign/meaning association, which essentially constitutes a "semiotic proposition" when considered from the receiving end of communication. By this, we mean that the initiator of communication primarily defines the systematic identity of linguistic signs by assessing the ease or the difficulty with which they may come to be accepted with the intended meaning in a recipient subsystem. If speakers and listeners are to understand each other, it is necessary that the sign/meaning association be observed by both systems simultaneously, which implies that the systemic positions are generated by the sign instead of the other way round. Speakers and listeners communicate because the semiotic forms construct them as such. Hence the term "replication" (Douay and Roulland, 2014: 102-114).

\subsection{The replication process and the Interlocutive Relation}

By questioning the replicability of semiotic propositions, the TIR necessarily imposes a shift in the way linguistic signs are to be analysed. They become "recipient-centred". This does not mean that they require the presence of an actual hearer, only that they are fundamentally designed to regulate and guide their own interpretation in another local subsystem. It is communication itself which is the organising principle of the system, not any reference to a pre-existing subjectivity. This prevents speaker and hearer to be treated as extrinsic users of the language and flesh and bone entities. Rather, it is posited that language deals with the complexity of the communication process by reducing it to a binary opposition distinguishing between an emission, or " $\alpha$-profile", and a reception, or " $\beta$-profile", thereby establishing two alternative voices representing all potentially competing subsystems. Both the $\alpha$ and $\beta$ profiles are bound to emerge because of the drive to communicate. $\beta$ is another aspect of $\alpha$ itself, a byproduct of its status as the initiator of communication. They are meant to capture the purely linguistic roles of "sender" and "recipient" (Douay, 2001: 83), and do not systematically correspond to the speaker/hearer dichotomy, which operates on an interpersonal, extrasystemic level' ${ }^{7}$. Douay and Roulland (2014) thereby stress that linguistic forms are always, and from the start, designed with a conversation partner in mind. Linguistic signs are both chosen so as to establish a connection with other subsystems and regulate the reproduction of meaning from one system to the next. How is this achieved?

21 By problematising hearer-reception, replication necessarily establishes relations of an "interlocutive" and "dialogical" nature (see Douay, 2001) between the emission and the 
reception profiles. The state of the $\alpha / \beta$ relations, which are communicated, or replicated, in the recipient subsystem, becomes crucial and is actually exploited by the emission-profile to influence reception and semantic interpretation. ${ }^{8}$ In other words, it is posited that, because linguistic signs serve to mark and reproduce different types of Interlocutive Relations (IR), they impose them into the hearer's subsystem. This is compelling as it guides towards specific interpretations. The TIR distinguishes three types of IR, related to three ways of achieving replication. Each favours certain types of meaning to be inferred from the replicated state of the IR.

Replication can indeed be achieved through direct acceptance of the semiotic proposition (i) or through negotiation between the two profiles (ii)-(iii). Each mode of replication sets up a specific "inferential frame" (see below and Section 5), and leads to different types of semantic interpretation of the linguistic sign.

(i) "C0-configuration", also called "Direct Interlocutive Relation" ('DIR'; see Douay, 2001: 83), refers to a state of the IR in which the two profiles "play an equivalent part" (Douay and Roulland, 2008) and come to direct agreement on reference. Such a configuration, which anticipates and imposes direct acceptance of the semiotic proposition, is normally minimally marked and indicates that no inferential effort is required in interpreting the meaning of the linguistic sign. It can be associated with different English forms like the $\varnothing$-determiner, proper names, the imperative and the Ø-ending of the simple present (Douay, 2000; Douay and Roulland, 2014). Pre-established harmony in the IR remains unchallenged, which corresponds to immediate replication of the semiotic proposition. Interpreting the linguistic sign, i.e. validating the semiotic proposition, is not an issue here, unlike $\mathrm{C} 1$ and $\mathrm{C} 2$ below. (ii) "C1-configuration" refers to a state of the IR characterised by a state of discordance to be dealt with between $\alpha$ and $\beta$. This implies a polarised IR highlighting the role of the emission profile, and is necessarily challenging to the reception profile. It is based on an 'associative pattern' (Douay, 2001: 84) whereby $\alpha$ elicits $\beta$ 's participation. This sets up an inferential frame characterised by 'duophony' (Douay, 2009: 24) and non-consensual, possibly polemical views on the semiotic proposition. The semantic interpretation of the linguistic sign is now clearly an issue and needs validating by the recipient as replication is explicitly marked as unfinished and disharmonious. This configuration of the IR has been associated with markers like A(N), THIS and ANY, for instance (Douay, 2000; Douay and Roulland, 2014).

(iii) "C2-configuration" corresponds to pre-eminence of the reception profile, which results in depolarisation and a pre-imposed concordant state of the IR. This results in a 'dissociative pattern' (Douay, 2001: 84), in which $\beta$-participation is no longer required. The $\alpha$-profile itself ceases to matter as well, since any potential disagreement is cancelled out. The two profiles have become almost indistinguishable. The inferential frame is now characterised by 'monophony' (Douay, 2009: 25). This leads to unity of views as regards the semiotic proposition, the interpretation of which has been turned into a special type of issue, a non-issue as replication has been completed and harmony restored. Validation of the semiotic proposition is now considered complete. This configuration of the IR has been associated with markers like THE, THAT, SOME and the preterite (Douay, 2000; Douay and Roulland, 2014).

\section{Data, methodology and limitations of the study}

The data used for our contrastive study of excuse me and (I'm) sorry within the framework of the TIR were extracted from the Corpus of Contemporary American 
English (COCA, Davies, 2008-) which is composed of over 560-million-word texts covering American English from the late $20^{\text {th }}$ century up until the present. COCA is evenly divided into the following five genres: spoken, fiction, popular magazines, newspapers and academic journals. The spoken part is composed of transcripts of conversations from different TV and radio programmes. The written part is based on short stories, novels, plays, different magazines from a wide range of domains, newspapers from across the US, and peer-reviewed journals.

The examples we will provide in Sections 5 to 7 are excerpts from both the spoken and some written parts of the corpus. Casual conversation is the prototypical speech genre in the context of which forms like (I'm) sorry and excuse me are most often studied. For this reason, the most part of our data illustrate spoken English, whether from the spoken part of COCA or from fictional dialogues contained in the written part of the corpus. However, we also found it interesting to occasionally provide a few excerpts from another non-conversational written genre, namely newspapers and magazines articles, because the argumentative function of some of the uses of (I'm) sorry in this particular context also supports and illustrates our hypothesis about its systematic opposition with excuse me (see examples (5) and (16) in sections 5 and 6, respectively).

The present paper is not a corpus study meant to supply information as to the overall frequency of excuse me and (I'm) sorry, their distribution across genders, age, etc. Rather, our interest lies in the comparison or, rather, the contrast between the different types of interlocutive relations that excuse me and (I'm) sorry encode on the level of the linguistic system, and which give rise to various pragmatic functions on a further level, i.e. in discourse.). ${ }^{9}$ We investigated the first 200 occurrences that the corpus search yielded of both excuse me and sorry. Out of these 400 occurrences, we mainly extracted the syntactic structures in which the Illocutionary Force Indicating Devices (Searle, 1969) (I'm) sorry and excuse me are most evident and stand alone. In other words, we excluded examples like "if you'll excuse me" and mainly focused on sentences in which excuse me and (I'm) sorry appeared in isolation. We considered very few syntactically complex constructions providing explicit reference to a potentially offensive event within the syntactic frame of the forms - e.g. excuse me for speaking bluntly to you / I'm sorry that I'm speaking bluntly to you. This gave us a total of 173 occurrences for excuse me and 87 for (I'm) sorry. We also conducted a separate search of excuse me as it appeared one to six words to the left or right of sorry in order to investigate the possible relevance of the order of the sequence $<\left(I^{\prime} m\right)$ sorry, excuse me $>$ vs. <excuse me, (I'm) sorry> (see Section 7).

The main reasons - apart from lack of space - for investigating the contexts in which (I'm) sorry and excuse me stand alone are their high frequency rate (see, among others, Deutschmann, 2003: 53) and the fact that in several excerpts, the speaker/writer uses excuse me immediately after (I'm) sorry or vice versa. It seems to us that these excerpts are particularly enlightening for the opposition we assume between these two forms (see Section 7).

Though (I'm) sorry and excuse me are not considered here as apology markers per se, our presentation of the data in Sections 5-7 will rely on various types of disruptive events as laid out in, e.g., Holmes (1995: 177), Aijmer (1996: 109), and (Deutschmann, 2003: 64). Holmes (1995: 178), for instance, distinguishes six major offence categories: inconvenience, space, talk, time, possessions and social gaffes. Aijmer (1996: 109) elaborated on Holmes' taxonomy and proposed an additional category labelled 
'inconvenience or impoliteness to another person'. Deutschmann (2003: 64) further refined these taxonomies in order to accommodate the range of apologies he encountered in the BNC corpus, "the aim of each category label [being] to capture the essence of the social situations which led to the apologies that appear in [his] corpus" (Deutschmann, 2003: 63).

Our purpose is not to discuss the relevance of these taxonomies, to modify or refine them, but rather to show that what we assume to be a systematic interlocutive opposition between excuse me and (I'm) sorry permeates several kinds of social situations in which various types of 'offences' might be performed, and accounts for the possible exclusion of (cf. Section 5), or at least the preference for (cf. Section 6), one of the two expressions in specific situations. In Section 7, we shall also try to explain the cooccurrence of the two forms in the two sequences < (I'm) sorry, excuse me> and <excuse $m e,(I ' m)$ sorry> which might otherwise be considered a priori as counter-examples to the assumption put forward in this paper.

\section{Excuse me vs. (I'm) sorry: In search of exclusive contexts}

The most serious difficulty when one considers the difference between excuse me and (I'm) sorry as IFIDs lies in identifying exclusive contexts that would automatically lead a speaker to select one of these two expressions and that one could confidently consider as revealing of their linguistic identity. We would like to start with Deutschmann's (2003: 74) remark that excuse me is "typically the form [...] uttered when a speaker want [s] to catch an audience's attention before making an announcement". We indeed consider that only excuse me is appropriate in (1)-(2), at least as an attention-getter, i.e. a device which is solely used to catch someone's attention and seek their participation in the exchange or situation:

(1) "Excuse me, miss?" I looked up to find a short, balding man in a tweed jacket standing at the counter. He was holding his hand over his nose like he smelled something terrible. "Yes?" I asked, taking a deep breath

Everything smelled fine to me. "There's a cat in here".

(2015 FIC Bk: DeathByCoffee)

(2) Jasmine: We're pregnant.

Erik: Oh, wow.

Jasmine: We better get engaged fast. Officially.

Erik: Yeah, yeah, yeah.

Jasmine: You don't seem excited.

Erik: I really, are you, are you sure these are, these are accurate?

Jasmine: Well, you know what, I have more. So, I will go take another one, okay? [...]

Erik is left alone and as they keep to themselves he becomes desperate for another woman's advice.

Erik: Excuse me, guys. Sorry to interrupt but I'm, like, freaking out. I need to talk to somebody.

(2014 SPOK: $A B C)$

In (1)-(2), speaker and hearer are strangers initially engaged in different occupations until the speaker initiates conversation. In (1), the bald man wishes to draw the girl's attention to the statement he is about to make, i.e. "there's a cat in here", and Erik in (2) addresses some strangers who are having a private conversation so as to get their opinion on the subject of marriage, which his girlfriend has just confronted him with. 
Note that we did not find any example of (I'm) sorry as an attention-getter in COCA among the first 300 occurrences that a corpus search of sorry yielded in the spoken part of the corpus, which would tend to confirm that it is not the preferred form in this situation.

However, initiation of conversation is not enough to automatically cause the speaker to prefer excuse me over (I'm) sorry, as demonstrated by the observation contained in (3):

(3) It's my experience that Brits tend to use 'sorry' a very great deal more often than Americans do, and in more contexts. My English office mate uses it all the time simply to get my attention ("Sorry, could you hand me the stapler?").

(https://www.lonelyplanet.com/thorntree/forums/speaking-in-tongues/topics/ michael-swan-s-golden-rules)

Even though the speaker in (3) seems to regard the use of sorry to initiate communication as a Briticism - a somewhat marginal phenomenon in his own version of English - we can wonder whether "Sorry, could you hand me the stapler?" is a counter-example to our first observation for excuse me or whether the sentence should be understood with a different implication in this context. Of course, we do not have enough contextual evidence to decide but we shall raise two questions at this stage: what does excuse me have, which (I'm) sorry does not, that makes it a preferred attention-getter? And how does one define the linguistic identity of (I'm) sorry?

To account for the (possibly exclusive) use of excuse me in (1) and (2), we propose to describe its ability to function as an attention-getter by assimilating it to a form which replicates a polarised IR between the two theoretical profiles $\alpha$ and $\beta$ (sender and recipient) - i.e. a $\mathrm{C} 1$ marker. Note that a neat speaker-hearer opposition is inherent to the situation of a request for attention and necessarily highlights the $\alpha / \beta$ opposition, which explains why excuse me would be the preferred form. In (1)-(2), this type of IR can easily be interpreted as a way to strike up a conversation between people. This can also be taken to echo the extra-linguistic disharmony engendered by the disruption caused by the speaker's breaking in. The polarised IR can thus be interpreted as an admission by the speaker that something annoying is taking place, and we see excuse me as a sign of shared interlocutive discordance, a way for the speaker to address the hearer on what is fundamentally a challenging mode, eliciting a sense of cooperation ${ }^{10}$ on her part in the forthcoming exchange.

We did not pinpoint specific types of offences that would automatically entail the use of $\left(I^{\prime} m\right)$ sorry to the exclusion of excuse me. However, as will be documented in Section 6, it seems that in situations in which the two expressions could otherwise be thought to be interchangeable, (I'm) sorry is often associated with a sense of continuity, as in (4), or closure and finality in the exchange, as in (5):

(4) "I thought about the reasons I like working at the restaurant. And even though it's only part-time, it's a pretty long list." She glances up, adding, "A good thing, but I'll try to keep it brief." A smile flickers across Dr. Lerner's face an instant before his cell phone pings a muted note and his smile fades. "I'm very sorry, Reeve. Please excuse me a second," he says, checking the screen. [...] He scowls at the phone, [...] and sets it on the corner of his desk. "I'm sorry, Reeve. Please continue."

(2013 FIC Bk: EdgeNormal)

(5) "We may be able to do other projects outside of maintenance," said state Department of Transportation Commissioner Russell McMurry in an exclusive interview with The Atlanta Journal Constitution. "But not like rebuilding 285 or something huge like that." Sorry, folks. A billion bucks just isn't what it used to be. Transportation consultants and state officials made it clear from the start of the 
debate over transportation funding last year that a billion dollars per year was the bare minimum needed just to bring the transportation system Georgia already has up to snuff.

(2015 NEWS: Atlanta Journal Constitution) dissociative, depolarised pattern whereby $\alpha$, i.e. the sender, no longer requires $\beta$ 's, i.e. the recipient's, participation. This is also in sharp contrast with the assumed duophonic nature of excuse me in (1)-(2) whereby $\alpha$ does clearly elicit $\beta$ 's participation, and we think example (4) provides a good illustration of the speaker's strategy in choosing (I'm) sorry. We analyse the first occurrence as a way for the speaker to cancel out Reeve's participation in the exchange and take control of the situation. Dr Lerner establishes a certain one-sidedness to their conversational exchange as he expects her to accept the upcoming state of affairs - his being distracted by his phone and consequently overlooking her needs - however disruptive this might be. But Dr Lerner then realises that Reeve will probably scowl at his unusual behaviour (it is a one-off event). So, by adding "excuse me" - which is not used as an IFID here - he then admits that she could resent the upcoming disturbance after all, as he "allows himself to be distracted" during their present session. Excuse me lets him impose a shared sense of competition in the interpretation of the situation. Reeve perfectly gets the message and obviously disapproves of his attitude (cf. "she stiffens"), which leads her to ask him if it is an emergency. Excuse me gives her enough leeway to object to being overlooked. The second occurrence of I'm sorry is meant to suggest that Dr Lerner is now putting an end to the conflicting situation by not answering his text message. The two interlocutors can now return (cf. "please continue") to a previous harmonious state in their relationship, when the psychiatrist was actually paying attention to his patient's narrative. Similarly, "sorry, folks" in (5) is a way to put an end to the ongoing debate, which is why we consider "excuse me, folks" to be inappropriate in this context in which the speaker is obviously trying to have the final say. Note that there is a sense of finality contained in his following statement, i.e. "a million bucks just isn't what it used to be".

In Section 6, we will provide more evidence supporting our analysis of (I'm) sorry as a form which replicates a depolarised IR. Recall that this 'monophonic' pattern (Douay, 2009: 25) downplays the role of the emission profile, precluding the recipient from any autonomous interpretation of the semiotic proposition. It thus makes room for an inferential frame characterised by unified views and newly-found consensus and anticipates full cooperation between sender and recipient (see Section 3). In terms of communication, this means that (I'm) sorry is fundamentally a marker of continuity, which is concerned with maintaining, and possibly terminating a pre-established IR. We thus align ourselves with Mattson Bean and Johnstone (1994: 75) who see sorrybased apologies as "a way of regaining the respondent's cooperation and ensuring that the interaction will continue."

In the next section, we compare the use of excuse me and (I'm) sorry in similar situations and show that textual evidence suggests that they are not completely interchangeable in that they elicit different interpretations. 


\section{Polarisation of the IR, or lack thereof}

's presence there is quite surprising, even at odds with the speaker's expectations. We assume that excuse me is meant to get the hearer's attention, but also to underline the exceptional nature of this kind of situation and indicate that the interpretation of what is going on will be considered an issue from now on. (I'm) sorry does not work well in this context, in which the speaker signals that she anticipates differing and potentially competing views on the situation. Indeed, the questions "who are you and what are you doing in my father's house? And what are you doing with my kitten?" highlight the sharp opposition between the speaker's mental system or logic and the hearer's, as shown by the use of the adversative conjunction but in initial position. In the speaker's view, there is probably no accounting for the hearer's having stolen into her father's house and taken care of her kitten, which is why she expresses strong protest - just like in a breach of consensus situation illustrated in (13), (14) and (16) below. For the hearer, however, the situation is probably not abnormal since she decided to break into a stranger's house. By replicating a polarised IR, the speaker draws the hearer's attention to the controversial nature of the situation and lays emphasis on her own viewpoint, i.e. a stranger should not be in her father's house doing what she is doing with the kitten. Excuse me is a signal to the hearer that they need to work out a common interpretation of what is going on, and it was chosen over $\left(I^{\prime}\right) m$ sorry so as to put the hearer in a position where she will have to provide an explanation.

It is in that respect only that we consider excuse me in (6) as an expression of apology. Note indeed that the verb excuse is a loanword from old French escuser which was itself borrowed from Latin excūsāre "release from a charge, excuse" (ex- "out, away" + causa "accusation, cause") (Barnhart, 2008: 353). The original meaning of the verb - "release from a charge" - sheds light on the core function of excuse me as an expression of confrontation between two entities - recall that excuse me is initially an imperative form -, which is why we take it to be a duophonic marker (see Section 3), i.e. a form which points to a disharmonious interlocutive relation between sender and recipient of the semiotic proposition and guides towards interpretations characterised by contrast, competition, defiance, disagreement, even insult, non-closure, imbalance or 
imperfectivity (Douay and Roulland, 2014: 156). This is therefore in sharp contrast with an altruistic view of apologising as an act that is "face-saving for the $\mathrm{H}$ [earer] and facethreatening for the S[peaker]" (Olhstain, 1989: 156-157).

It seems that what really causes the speaker to choose excuse me over (I'm) sorry in (6) is not just the situation of a request for attention. Polemical intent or lack thereof also appears to be a determining factor ${ }^{11}$ and we propose that it should be taken into consideration when studying the two formulae in different environments. In the rest of this paper, we will thus try to argue that exclusive contexts for excuse me and (I')m sorry should not rely on typical extra-linguistic situations or offenses for their definition, such as requests for attention, hearing offenses, breech of consensus, interruption, etc. Rather, we think that there is enough co-occurring linguistic evidence to think that what defines a preferred context is fundamentally the wish to establish a polarised or depolarised IR in the interpretation of the linguistic situation.

Consider (7) and (8) in which excuse me and (I'm) sorry occur in different contexts. They are not interchangeable, but why is this so? We take (7) to be charged with polemical intent as the speaker obviously wishes to highlight a competition between her views and Kerbey's and therefore relies on a polarisation of the IR, of which we take excuse me to be symptomatic. Conversely, sorry in (8) occurs in an apparently depolarised, nonpolemical context, in which excuse me would entail a different interpretation

(7) Greig: Happy birthday, young man.

Will: You mean I finally get a gun of my very own?

Greig: Yep. You're old enough now.

Will: Awesome.

Kerbey: Excuse me but seriously? You're giving a gun as a birthday present to a little kid?

Greig: Don't worry. I'll teach him everything he needs to know to be safe.

Kerbey: Oh, my gosh. Is this even legal?

(2015 SPOK: $A B C$ )

(8) If you've uploaded any music into the Music folder in OneDrive it will add those songs, too, complete with metadata and album art that it can cull from the Internet. Ideally, of course, you'll already own an Xbox (sorry, Groove) Music pass, and can stream as much as you'd like.

(2015 MAG: PC World)

Kerbey's purpose in (7) is to make Greig aware that giving a gun as a birthday present to a kid is pure folly in his view. Kerbey wants to show his total disagreement with Greig's decision, which is deeply questionable to him (cf. "Oh, my gosh. Is this even legal?"). Hence the use of excuse me, which imposes the idea that the two profiles of communication are now explicitly engaged in bona fide dialogue and that the interpretation of what they are discussing is purportedly of a non-consensual and even controversial nature. (I'm) sorry but seriously? would be inappropriate in this passage note for that matter that we did not retrieve any occurrences of the sequence in our sample or in COCA as a whole.

By contrast, it seems that excuse me would be inappropriate in (8) in which the speaker/ writer considers that her mistake - talking about an Xbox Music pass instead of a Groove Music pass - is not a big issue, though rephrasing is considered a better solution. We analyse sorry as a monophonic form, i.e. a way to associate the two phrases, i.e. Xbox Music pass and Groove Music pass, with potentially discordant voices - $\alpha$ and $\beta$ - while subsequently refusing any real polarisation of the interlocutive relation. Both options are therefore ultimately put on the same footing and intended to be 
interchangeable. The speaker spontaneously opts for the former while the addressee would probably prefer the latter, but she indicates that there is no competition between the recipient and herself on this point.

We now would like to put our hypothesis to the test by comparing the use of excuse me and (I'm) sorry when they occur in the same situations in an attempt to show that polarisation of the IR acts as the most important context-defining element, regardless of what happens in the real world. ${ }^{12}$

Excuse me and (I'm) sorry can both occur in the situation of a hearing offence, for instance. As argued above, we think that the choice between the two formulae depends on the speaker's choice to rely on a polarised or depolarised IR, i.e. to impose a challenging or non-challenging IR. Let us start with sorry which is used as a simple, neutral cue for repetition, with no polemical intent in (9):

(9) Kathie Lee Giford: Does Hoda prefer red or white wine?

Nora-Moore: Sorry, say that again.

Kathie Lee Giford: Does Hoda like red wine or white wine?

(2015 SPOK: NBC)

Nora could obviously not hear Kathie's question, which is why she is asking her to repeat it. This could be seen as disrupting the flow of conversation, but in fact the request for repetition ensures that "talk flows smoothly" (Mattson Bean and Johnstone, 1994: 62) by allowing the speaker to resume her conversation with the hearer on good terms. The request for repetition is to be treated as insignificant, i.e. as having no impact on the relation between speaker and hearer, and it is thus a way to "keep the communicative system working" (Mattson Bean and Johnstone, 1994: 62) despite its potentially disruptive nature. Excuse me seems inappropriate as a cue for repetition and would establish a slightly different context.

Indeed, when a hearing offence consists in asking someone to provide an explanation or justification for some terms that were misunderstood, as in (10)-(11), or when one expresses "disbelief" (Deutschmann, 2003: 73) as in (12), excuse me seems to be a preferred form:

(10) “It hasn't responded to any of the usual antivirals, either. I've tried oseltamivir and zanamivir, but neither of those could stop it from escaping from its host cell. It replicates like rabbits on fire." "Excuse me?" said Epiphany. "Rabbits on fire? Well, you know what I mean. Rabbits on speed. Rabbits on Viagra. Rabbits behaving like rabbits. I'm too tired to be logical."

(2015 FIC Bk: Plague of the Manitou)

(11) I was confused for exactly one second, because I never made detective and so technically I never really worked on a 'case'. But as soon as I connected the name to the crime, it all came back to me. You don't see a crime scene like that without remembering it for the rest of your life. "Darryl King," I said. "In the train station." "You forgot "With the knife." "Excuse me?" "Sorry, bad joke. You know, like in that game? Colonel Mustard, in the library, with the lead pipe?"

(2013 FIC Bk: Let it burn)

(12) "Good at what you do?" Gigi's furrowed expression as she sat back down on the sofa inspired doubt in Corina. "Well, of course you are. And by the way, splendid of you to step up after Carly left. The bull pen loves you. Who knew you were so good with details?" "Me." "But of course." "That's why I think you should just give me..." "Corina, I hired you to spice things up." "Excuse me?" "Girl, you used to pal around with Paris Hilton, and I bet if I snagged your iPhone, you'd have a Kardashian or two in your contacts." "Hello, do you not remember my life for the past five years?" 
(2015 FIC Bk: HowCatchPrince) own system - which is not surprising since even the interlocutor acknowledges she is not being logical - and that she is appealing to the hearer, seeking the latter's participation for clarification. The disruptive nature of the repetition request is now made obvious to the hearer and the interpretation of the expression "rabbits on fire" is turned into a common issue. Excuse $m e$ is thus used to lay stress on the misunderstanding between speaker and hearer, which is a form of disharmony between the two. In our view, what excuse me imposes to both speaker and hearer is an imbalanced IR, since the meaning of the term has become an issue, something to be negotiated by the conversation partners. Similarly, in (11), the policeman "who never made detective" obviously does not get the joke. Interestingly, the "joker" does not interpret excuse me as a pure request for repetition but rather as an invitation to explain herself and clarify the reference to the game Cluedo, which she does (cf. "Colonel Mustard, in the library..."). Again, we think that this is so because excuse me evokes two competing linguistic systems. By contrast, when she later says "I'm sorry, bad joke", it is the sign that the speaker anticipates some sort of consensus as to the quality of the joke. "Excuse me", which we see as a way to voice two potentially conflicting views on the situation, seems unlikely at this point.

Conversely, (I'm) sorry is likely to be inappropriate in (12) because Corina expresses her surprise at Gigi's opinion that she hired her to "spice things up". She obviously disagrees on the semiotic proposition, i.e. the interpretation given to the hiring process, which is marked as a controversial and conversationally disruptive issue (cf. "Hello, do you not remember my life for the past five years?"). The whole point of excuse me here is to flag the potentially conflicting situation as clear-cut confrontational context for the hearer.

Let us now turn to the use of excuse me and (I'm) sorry in situations involving breach of consensus offences (Deutschmann, 2003: 64), e.g. situations in which interactants disagree, contradict, reprimand or challenge one another. In (13)-(14), excuse me could be understood as an anticipatory 'face attack' apology, i.e. an apology "made before or after [a] premeditated attack on a hearer's positive face needs" (Deutschmann, 2003: 74), in other words an attack which might counter one's desire to be liked, appreciated, approved, etc. (Brown and Levinson 1987).

(13) "Take it easy, kid. It's not so bad." "Not so bad. Excuse me, did you just say the words 'not so bad'? You don't understand, Joe, see, if a guy vomits on the sidewalk, you don't say, 'Oh, hey, it's not so bad, there's some ham in there.' It's fucking vomit, okay? This is bad."

(1991 FIC MOV: The Last Boy Scout)

(14) Since there was no explaining yourself on why you are so sassed up or mad I will have to guess, and I will guess it is probably because of the hooker thing. Or courtesan, sorry. Yes I painted you as a hooker or courtesan and totally naked and waiting in the bed (...) Should I say I'm sorry? I should not! I shouldn't say I'm sorry because, excuse me, you are a hooker. Right? I only painted the truth.

(2012 FIC Iowa Review)

In (13), excuse me is not used as a request cue for repetition. The speaker has perfectly heard and understood Joe when he said "it's not so bad". He actually repeats Joe's words himself ("not so bad. Excuse me, did you just say the words "not so bad'?"). Nor is excuse me meant to be understood as a 'real apology' (cf. Deutschmann, 2003: 44-46, 69). 
We think that excuse me, in this very expressive, polemical context (cf. "it's fucking vomit"), does not merely "put slightly more distance between the speaker and the addressee [than sorry does]" (Borkin and Reinhart, 1978: 62) but rather emphasises the disagreement and disharmony between the two interlocutors caused by their differing views on the relevant matter, Joe's opinion - "vomiting is "not so bad" - being most controversial to the speaker who thinks otherwise (cf. "you don't understand", "this is bad").

(14) is an excerpt from a letter sent by a male painter to his female model, Victorine, in response to a furious letter she had sent him previously. Excerpts from Victorine's letter are provided in (15):

(15) You paint like a porcupine.

I had occasion to go see this painting Olympia for myself. And I was astounded.

Indignant. What were you thinking?

Next time you go to the Salon, go with your pants off. Then you'll know how I feel.

(2012 FIC Iowa Review)

At first, the speaker in (14) anticipates that Victorine will feel offended because of his reference to "the hooker thing", but by rephrasing, i.e. "or courtesan, sorry", he pretends to have made a concession to the hearer in his choice of words, so as to avoid hurting her feelings. At the end of his turn-taking, he no longer discusses the potentially offensive nature of the term hooker itself, but the right for him to paint the woman as such a person (cf. "Should I say I'm sorry? I should not!"). Interestingly, he then goes on to use excuse me to show that he stands his ground in the face of a most upset Victorine who obviously objects to seeing herself pictured as a courtesan (cf. (15)). That is when he chooses to use the word hooker again. The speaker now emphasises his own initial judgment as being the right one, thus undermining the hearer's. We analyse the move from sorry to excuse me as one of depolarisation to repolarisation of the IR. By now refusing to "say sorry" and using excuse me, he comes across as extremely provocative, to the point of being insulting. We also hypothesise that the use of excuse me in (13)-(14) leads the hearer to infer that some response is expected by the speaker (cf. "okay?" in (13), and "right?" in (14)), and gives rise to a sense of imperfectivity in the exchange (Douay and Roulland, 2014: 156). Excuse me is understood as a cue that the conversation/argument is not over, which gives enough leeway for a possible subsequent retort.

By contrast, we assume that when a speaker expresses disagreement with a hearer, she may use sorry to impose some kind of agreement between speaker and hearer. This enables her to give her side of the story without polemical intent, thus sounding less controversial, as in (16) in which sorry functions as a disarmer (Edmondson, 1981: 282), i.e. an anticipatory strategy preparing the hearer for a potentially unwelcome statement:

(16) Oscar prep takes at least three hours. "Of course they look flawless. Who wouldn't?" Brooke says. "Can you imagine how amazing you would look (with that much help)?" Every nominee has a speech scripted, just in case. We love to think we're seeing spontaneous tears and authentic astonishment up there on stage. But, sorry it's not true. "Everyone, whether they admit it or not, has a speech prepared in the event of winning an Oscar. We practice them in the shower, in the car, in the middle of the night, when we think no one's listening," says industry publicist Bumble Ward.

(2015 NEWS: USA Today) 

such, is representative of a written genre. (13)-(14) are also extracted from written data but are more representative of a spoken genre because they are excerpted from fictional dialogues. However, sorry in (16) has an argumentative function which is worth comparing to that of excuse me in (13)-(14), which are other examples of breech of consensus. Sender and recipient roles in newspaper articles are quite evidently taken up by journalist and potential readers, respectively. The former deals with more or less debatable issues and sender and recipient(s) are not necessarily expected to think alike. There is a pre-existing situation of argumentative disruption to be dealt with in the real world. It is not unreasonable to think that the journalist in (16) could potentially decide to say either (I'm) sorry or excuse me. She contradicts (cf. "but it's not true") the general view that is held about "Oscar prep" and we propose that she uses sorry instead of excuse me to avoid sounding too polarising and alienate her readership as sorry indicates that the journalist tries to deconstruct the contextually pre-established duologic IR and return to monophony by voicing what is now presented as a more or less unified view on the issues under discussion. It is thus a way for her to mitigate the challenging effect of the opposition, to keep a low profile, and "to establish cooperative rapport" (Mattson Bean and Johnstone, 1994: 59) with the reader.

Let us now consider one last type of situation, which involves what Deutschmann calls a 'minor accident' (2003: 64). One can infringe on somebody else's personal space by bumping into them, walking too close to them, taking their seat, etc. (Goffman, 1971). Note that the accident may have just occurred or be about to occur. While Swan (2005: 535) associates excuse me with forthcoming offenses and (I'm) sorry with pre-validated offenses in British English, American usage appears to be slightly different. Indeed, Borkin and Reinhart (1978: 61) seem to agree that the latter can be analysed as an expression of regret used "in remedial interchanges when a speaker's main concern is about a violation of another person's right or damage to another person's feelings" while the latter constitutes "a formula to remedy a past or immediately forthcoming breach of etiquette" for American speakers. This suggests that one could preferentially - in British but not necessarily in American English - associate excuse me with anticipation of the offense, as in (17). By contrast, (I'm) sorry is preferentially used in both varieties after the offence has taken place, as in (18):

(17) "Excuse me, ma'am." Bell stepped aside, realizing that she was blocking the narrow sidewalk and thus impeding access to the store. Moving past her, a heavy man in a green plaid wool coat pulled at the ragged bill of his Peterbilt cap. "Ma'am," he repeated.

(2015 FIC Bk: LastRaggedBreath)

(18) "Sorry!" A lady bumped Aidan from behind and was quick to apologize. A moment later a man elbowed him in the ribs. No apology there.

(2014 FIC Bk: No sunshine when she's gone)

The obvious function of excuse me in (17) is to let the hearer know that the speaker is aware of the disturbance he might create by possibly bumping into her or by asking her to move aside. Simultaneously, the hearer is meant to understand that she is in the speaker's way. We think that if excuse me is felicitous in anticipatory offences, it is because the speaker imposes hearer-involvement in interpreting the situation. By replicating a polarised IR, the speaker leads the hearer to infer that they are actually competing for space. 
61 By contrast, the speaker in (18) says sorry retrospectively, that is after bumping into the hearer. We hypothesise that sorry imposes complete previous agreement on the 'body accident' (Deutschmann, 2003: 67) for which the speaker alone is responsible, which explains why it is the preferred form in post-bumping situations. The speaker admits to the offense and the hearer "does not have any say" in its interpretation. As a result, things can now smoothly go back to normal. In other words, by relying on sorry the speaker tries to distance herself and the hearer from the offence..$^{13}$

Note that it is the hypothesised polarisation and depolarisation of the IR by excuse me and (I'm) sorry, respectively, which cause the body accident situation involved to be interpreted as almost exclusive contexts in the case of (17) and (18). The fact that the formulae are uttered before or after the event is not the most determining factor, as demonstrated by American usage ${ }^{14}$. Thus we do not think that (19) constitutes a counter-example to our analysis. However tempting it is to associate (I'm) sorry with the idea that the offence has been prevalidated in the speaker's mind and excuse me with new or forthcoming offences, the latter can actually occur after someone has been bumped into:

(19) She saw his chest expand with a deep breath just as she was bumped roughly from behind. "Excuse me, Miss Benbridge." Startled, her gaze turned to identify the offending individual and found a wigged man wearing puce satin. She muttered a quick dismissal of his concern, managed a brief smile, and swiftly returned her attention to the masked man.

(2017 FIC Bk: A passion for him)

63 Our claim enables us to propose that excuse me was chosen over (I'm) sorry because the offending man needed enough leeway to voice "his concern" and to leave Miss Benbridge a chance to react to the offence, which she was obviously not really interested in doing initially. She nonetheless had to "voice a quick dismissal of his concern", which (I'm) sorry would not necessarily have led her to do. We think that she analyses excuse me as a clue that the speaker expects her to react in some way.

\section{Joint occurrences}

As mentioned in Section 4, we found it enlightening to examine examples of cooccurrence of excuse me and I'm sorry. A search throughout COCA returned 45 relevant occurrences. How do these fit in with our analysis? One may assume that the cooccurrence of excuse me and (I'm) sorry is meant to intensify the apologetic force of the utterance - provided, of course, that the forms are used as 'real apologies' (cf. Deutschmann, 2003: 44-46, 69). This is a possible interpretation of (20):

(20) She got on the bus wearing the same clothes she'd had on for three days. She looked for a window seat. She found one in the middle, next to another woman who was cradling a young boy. As she climbed over the boy and woman to get to her seat, Nichelle held her arms down to her sides, and said, "Sorry, excuse me. I'm sorry." She was apologizing for her body's odor.

(2016 FIC Callaloo)

But we also came across other examples of co-occurrence of excuse me and (I'm) sorry in which the linguistic environment supports the idea that a speaker uses excuse me to dwell on interpersonal conflict or highlight the need for cooperation in communication, whereas (I'm) sorry downplays conflict or takes cooperation for granted in interpersonal exchanges. We think that the order of the sequence <excuse 
$m e$, (I'm) sorry> or <(I'm) sorry, excuse me> is of paramount importance in such circumstances.

First, consider (21) which illustrates the sequence <excuse me, (I'm) sorry>:

(21) Neil Minkoff: You know, when I watched it, what I - the message I got was, wow. Somebody's really worried about the enthusiasm gap and because nobody on my side of the aisle is saying, hey, guys, wake up. Pay attention.

Jimi Izrael: Clint Eastwood.

Arsalan Iftikhar: Yeah.

Jimi Izrael: Excuse me. I'm sorry. Go ahead.

Neil Minkoff: No one's saying pay attention. People, you know, on one side of the aisle can't wait to go out and vote.

(2012 SPOK: NPR)

Interruptions - which are part of Deutschmann's (2003) 'Lack of consideration' or Holmes (1990: 177) and Aijmer (1996: 109) 'talk' offences categories - are particularly interesting, since they provide a context in which communication itself lies at the core of the linguistic exchange, a configuration that we find especially revealing within the TIR framework. In our analysis, Jimi in (21) uses excuse me to show that he is aware of the disharmony caused by his interrupting Arsalan, who was beginning to speak, after he himself had interrupted Neil Minkoff. Saying "I'm sorry" afterwards suggests that Jimi wants Neil to resume his previous line of conversation (cf. "go ahead"). The interruption opposing speaker and hearer is over at this stage, and it is supposed to have been harmoniously dealt with. The use of sorry after excuse me clearly has a conclusive effect and confirms that it is "a resource orienting toward progressivity of and closing the apologetic encounter", in other words "a ready-made resource serving the preference for continuation and coherence in conversation" (Fatigante and al, 2016: 45). The reverse sequence <I'm sorry. Excuse me. Go ahead $>$ would probably sound awkward. On the contrary, by using (I'm) sorry, the speaker authorises the hearer to continue on, unchallenged, thanks to a depolarised IR. It indicates that sender and recipient can now move on to another topic.

In (22)-(24), on the other hand, excuse me and sorry appear in reverse sequence. Again, we think that the order <sorry, excuse me> was not chosen randomly:

(22) Morgan: You're in good nick for 86, don't you?

E. Edwards: Sorry, excuse me.

Morgan: You're in good nick. You are in good shape.

E. Edwards: Well, yes. I am very fortunate.

(2013 SPOK: CNN)

(23) Diane Sawyer: You've mentioned health care, and I just want to summarize your position, which is really dangerous, because I'm going to get it wrong. But it's basically to eliminate Medicare, replace it with...

Mr Bradley: No, no.

Sawyer: Medicaid, sorry. Medicaid, excuse me. Definitely different.

(1999 SPOK: ABC_GMA)

(24) Joseph paused before answering, but when he finally opened his mouth to speak, his father's mouth opened simultaneously - forced to do so by a large belch that filled the kitchen with the stench of beer. Peter looked down at his feet just in time to avoid the look of disgust that enveloped Joseph's face. "Sorry. Um, excuse me, I mean."

(2008 FIC Bk: Passin')

In (22), Morgan uses an expression which E. Edwards is obviously not familiar with, which leads Morgan to clarify it in the following line. We assume that E. Edwards chose 
to say "excuse me" just after saying "sorry" because he realised that saying "sorry" would lead the hearer to merely repeat the same expression without actually explaining. Note for that matter that E. Edwards was only able to respond to Morgan's initial question "you're in good nick for 86, don't you?" once Morgan had rephrased the expression "in good nick" into "in good shape". In (23), it seems that the speaker first says "sorry" because she mistook Medicaid for Medicare until she realises that the use of sorry is not the most appropriate strategy for dealing with the 'name offence' and that her mistake really is an issue for the hearer (cf. "no, no"), which leads to the additional comment "definitely different". Finally, (24) is an illustration of a social gaffe, i.e. belching. Peter breaks "a social etiquette rule relating to socially frowned upon behaviour" (Holmes, 1990: 180; cf. also Aijmer, 1996: 109; Deutschmann, 2003: 64). He first says sorry to apologise for what he initially thinks he and the hearer will not consider a controversial situation, but the look of disgust on the hearer's face shows otherwise. He is thus led to rephrase ("excuse me, I mean") his apology after realising that his loud belching is definitely controversial for Joseph, hence the need to acknowledge that he is to be involved in the interpretation of the situation. Peter probably feels that excuse me is more appropriate at this stage because it allows for the common articulation of two implicit and contrasting viewpoints in the conversation, one (Peter's) that holds the belief that "a loud belch is a very minor offence and the hearer will not question my view that apologising for it is a matter of routine" and one (Joseph's) that supposedly thinks that "a loud belch should be severely frowned upon as an offence that the interlocutor must remedy."

\section{Conclusion}

70 Although we generally agree with Jucker and Taavitsainen's (2008: 229) observation that it is "difficult to define a functional common core to all realizations of what are commonly called "apologies", we hope to have shown that it is not completely relevant to the study of excuse me and (I'm) sorry. We believe that there is a certain circularity in trying to define the linguistic identity of both expressions by treating them as markers of apology, and find it surprising that they quite commonly appear in nonapologetic situations. This logically leads to questioning the relevance of what is called an "apology" in the first place, a course of action followed by other scholars (Deutschmann, 2003, among others).

71 We have been following a different path here. Our hypothesis, which is based on Douay and Roulland's (2014) TIR framework, gives a central role to the recipient/hearer, not on a discursive level, but on the systematic level of language organisation. This nonreferential framework has enabled us to propose - on the basis of contextual evidence that excuse me and (I'm) sorry do not encode, or contain in themselves, any reference to a detrimental or offensive event, the seriousness of which could be assessed by flesh and blood beings, the speaker and hearer. Rather, we have been claiming that they indicate that what is at stake is the potentially conflicting interpretation of an extralinguistic event that may fall under different categories, e.g. breach of consensus offences, hearing offences, social gaffes, requests, competition for space, etc.. The nature of the situation itself and its supposed seriousness, or lack thereof, does not appear sufficient to fully define exclusive contexts for excuse me and (I'm) sorry. However, on the basis of data extracted from COCA, we claim that linguistic clues 
suggest that the two expressions influence hearer-interpretation of the situation in a different manner. We therefore think that preferred contexts of use should be defined in terms of polarisation or depolarisation of the IR.

In particular, we have tried to show that excuse me replicates a discordant sender/ recipient relation, which leads the hearer to infer that, by highlighting an opposition between $\alpha$ and $\beta$, the speaker wishes to establish a connection with her. For example, this may be taken to mean that the speaker wishes to request hearer-participation in the construction of a sincere apology, elicit cooperation or, on the contrary, exacerbate what separates them in a polemical context, even sound insulting. By contrast, (I'm) sorry imposes a concordant sender/recipient relation, which leads the hearer to infer that, for some reason, the speaker wishes to downplay any opposition between $\alpha$ and $\beta$. This may be inferred to mean that she no longer needs hearer-participation in the construction of a sincere apology, that cooperation is taken for granted, and that the situation or conversation can resume its normal course after a disruption. Whatever is polemical in other situations is, more or less strategically and sincerely, glossed over.

At this stage, further work will have to be done in order to see whether an analysis of the type we propose here is appropriate for other IFIDs like pardon (me), for instance.

\section{BIBLIOGRAPHY}

Aijmer, Karin. 1996. Conversational Routines in English. Convention and Creativity. Longman: London.

Aijmer, Karin. 2018. Positioning of self in interaction. Adolescents' use of attention-getters. In K. Beeching, C.Ghezzi and P. Molinelli (eds.), Positioning the Self and Others. Linguistic Perspectives, 177-195. Amsterdam: John Benjamins.

Arundale, Robert B. 1999. An alternative model and ideology of communication for an alternative to politeness theory. Pragmatics 9 (1): 119-153.

Arundale, Robert B. 2006. Face as relational and interactional: A communication framework for research on face, facework, and politeness. Journal of Politeness Research: Language, Behaviour, Culture 2 (2): 193-216.

Arundale, Robert B. 2008. Against (Gricean) intentions at the heart of human interaction. Intercultural Pragmatics 5: 231-260.

Arundale, Robert B. 2010. Constituting face in conversation: Face, facework and interactional achievement. Journal of Pragmatics 42: 2078-2105.

Bamgbose, Ayo. 1994. Politeness across cultures: Implications for second language teaching. In J.E. Alatis (ed.), Georgetown University Round Table on Languages and Linguistics, 17-27. Washington D.C.: Georgetown University Press.

Barnhart, Robert K. (ed.). 2008. Chambers Dictionary of Etymology. Finland: Bookwell Ltd. 
Blum-Kulka, Shoshana and Elite Olshtain. 1984. Requests and apologies: A cross-cultural study of speech act realisation patterns (CCSARP). Applied Linguistics 5 (3): 196-213.

Blum-Kulka, Shoshana, Juliane House and Gabriele Kasper (eds.). 1989. Cross-Cultural Pragmatics: Requests and Apologies. Norwood, NJ.: Ablex.

Borkin, Ann and Susan M. Reinhart. 1978. Excuse me and I'm sorry. TESOL Quaterly 12 (1): 57-69.

Brown, Penelope and Stephen C. Levinson. 1987. Politeness: Some Universals in Language Usage. Cambridge: Cambridge University Press.

Couper-Kuhlen, Elizabeth and Margret Selting (eds.). 2004. Studies in Interactional Linguistics. Amsterdam: John Benjamins.

[dataset] Davies, Mark. 2004- BYU-BNC. (Based on the British National Corpus from Oxford University Press). Available online at https://corpus.byu.edu/bnc/.

[dataset] Davies, Mark. 2008- The Corpus of Contemporary American English (COCA): 560 million words, 1990-present. Available online at https://corpus.byu.edu/coca/.

Deutschmann, Mats. 2003. Apologising in British English (Skrifter från moderna spark 10). Institutionen för moderna spårk, Umeå: Umeå University.

Douay, Catherine. 2001: Grammar-and-interlocution: English articles as markers of recipient role. Revue Québécoise de Linguistique 29 (2): 79-94.

Douay, Catherine. 2005. Un autre point de vue sur have. CORELA 3 (1). Downloadable at http:// corela.revues.org/488.

Douay, Catherine. 2009. Would you vote for Obama if he were white ? L'alternance were/was et la problématique de l'altérité. Anglophonia/Sigma 13 (26): 247-266. Downloadable at

http://journals.openedition.org/anglophonia/914.

Douay, Catherine and Daniel Roulland. 2008. L'Autre dans la langue : De la co-énonciation à l'interlocution. L'Autre / The Other. Revue du GRAAT 38: 15-33.

Douay, Catherine and Daniel Roulland. 2014. Théorie de la Relation Interlocutive. Sens, Signe, Réplication. Limoges: Lambert-Lucas.

Drew, Paul, Alexa Hepbum, Piera Margutti and Renata Galatolo. 2016. Introduction to the special issue on apologies in discourse. Discourse Process 53 (1-2): 1-4.

Edmonson, W.J. 1981. On saying you're sorry. In F. Coulmas (ed.), Conversational Routine. Explorations in Standardized Communication Situations and Prepatterned Speech, 273-288. The Hague: Mouton de Gruyter.

Fatigante, Marilena, Federica Biassoni, Francesca Marazzini, and Pierangela Diadori. 2016. Responsibility and culpability in apologies : Distinctive uses of 'sorry' versus 'I'm sorry' in apologizing. Discourse Process 53 (1-2): 26-46.

Ford, E.C. 1993. Grammar in Interaction. Cambridge: Cambridge University Press.

Ford, E.C. and J. Wagner. (eds.). 1996. Interaction-based studies of language. Special Issue of Pragmatics 6 (3).

Fraser, Bruce. 1981. On apologizing. In F. Coulmas (ed.), Conversational Routine. Explorations in Standardized Communication Situations and Prepatterned Speech, 259-271. The Hague: Mouton de Gruyter. 
Galatolo, Renata, Biagio Ursi and Ramona Bongelli. 2016. Parasitic apologies. Discourse Process 53 (1-2): 97-113.

García, Carmen. 1989. Apologizing in English. Politeness strategies used by native and non-native speakers. Multilingua 8 (1): 3-20.

Gardiner, Alan. 1932. The Theory of Speech and Language. Oxford: Clarendon Press.

Goffman, E. 1971. Relations in Public. Microstudies of the Public Order. London: Penguin.

Goodwin, Charles. 1981. Conversational Organization: Interaction between speakers and hearers. New York: Academic Press.

Grainger, Karen and Sandra Harris. 2007. Special Issue: Apologies. Introduction. Journal of Politeness Research 3: 1-9.

Grice, Herbert Paul. 1975. Logic and conversation. In P. Cole and J.L. Morgan (eds.), Syntax and Semantics: Speech Acts, Vol. 3, 41-58. New York: Academic Press.

Haugh, Michael. 2007. The discursive challenge to politeness research: An interactional alternative. Journal of Politeness Research: Language, Behavior, Culture 3 (2): 295-317.

Holmes, J. 1990. Apologies in New Zealand English. Language in Society 19 (2): 155-199.

Horn, Laurence R. 1984. Toward a new taxonomy for pragmatic inference: Q-based and R-based implicature. In D. Schiffrin (ed.), Meaning, Form and Use in Context: Linguistic Applications, 11-42. Washington D.C: Georgetown University Press.

Jucker, Andreas H. 2018. Apologies in the history of English: Evidence from the Corpus of Historical American English (COHA). Corpus Pragmatics 2: 375. https:// doi.org./10.1007/s41701-018-0038-y.

Jucker, Andreas H. and Irma Taavitsainen. 2008. Apologies in the history of English: Routinized and lexicalized expressions of responsibility and regret. In A.H. Jucker and I. Taavitsainen (eds.), Speech Acts in the History of English, 229-243. Amsterdam: John Benjamins.

Kohnen, Thomas. 2017. Non-canonical speech acts in the history of English. Zeitschrift für Anglistik und Amerikanistik 65 (3): 303-318.

Lambrecht, Knud. 1994. Information Structure and Sentence Form: Topic, Focus and the Mental Representations of Discourse Referents. Cambridge: Cambridge University Press.

Leech, Geoffrey. 2014. The Pragmatics of Politeness. New York: Oxford University Press.

Levinson, Stephen C. 2000. Presumptive Meanings: The Theory of Generalized Conversational Implicature. Cambridge, MA: Massachusetts Institute of Technology Press.

Lutzky, Ursula and Andrew Kehoe. 2016. “Oops, I didn't mean to be so flippant”. A corpus pragmatic analysis of apologies in blog data. Journal of Pragmatics 116: 27-36.

Margutti, Piera, Véronique Traverso and Rosa Pugliese. 2016. I'm sorry 'about that': Apologies, indexicals and (unnamed) offences. Discourse Process 53 (1-2): 63-82.

Mattson Bean, Judith and Barbara Johnstone. 1994. Workplace reasons for saying you're sorry: Discourse task management and apology in telephone interviews. Discourse Processes 17: 59-81.

Meier, A.J. 1992. A sociopragmatic contrastive study of repair work in Austrian German and American English. PhD dissertation, University of Vienna.

Meier, A.J.. 1998. Apologies: What do we know? International Journal of Applied Linguistics 8 (2): 215-231.

Mills, Sara. 2003. Gender and Politeness. Cambridge: Cambridge University Press. 
Mills, Sara. 2011. Discursive approaches to politeness and impoliteness. In Linguistic Politeness Research Group (eds.), Discursive Approaches to Politeness, 19-56. Berlin: Mouton de Gruyter.

Ochs, E., E.A Schegloff and T.A Thompson (eds.). 1996. Interaction and Grammar. Cambridge: Cambridge University Press.

Ogiermann, Eva. 2009. On Apologising in Negative and Positive Politeness Cultures. Amsterdam: John Benjamins.

Page, Ruth. 2014. Saying sorry: Corporate apologies posted on Twitter. Journal of Pragmatics 62: 30-45.

Papafragou, Anna. 2018. Pragmatic development. Language learning and development 14 (3): 167-169.

Rhys, Catrin S. 2013. Choosing not to repair: Sorry as a warrant for interactional progress. Research on Language and Social Interaction 46 (1): 84-103.

Robinson, Jeffrey D. 2004. The sequential organization of "explicit" apologies in naturally occurring English. Research on Language and Social Interaction 37: 291-330.

Schegloff, E.A. 1996. Turn organization: One intersection of grammar and interaction. In E. Ochs, E.A. Schegloff and T.A. Thompson (eds.), Interaction and Grammar, 52-133. Cambridge: Cambridge University Press.

Searle, J.R. 1969. Speech Acts. An Essay in the Philosophy of Language. Cambridge: Cambridge University Press.

Sperber, Dan and Deirdre Wilson. 1986. Relevance: Communication and Cognition. Oxford: Blackwell. Swan, Michael. 2005. Practical English Usage. $3^{\text {rd }}$ Edition. Oxford: Oxford University Press.

Taavitsainen, Irma and Andreas H. Jucker. 2008. Speech acts now and then: Towards a pragmatic history of English. In A.H. Jucker and I. Taavitsainen (eds.), Speech Acts in the History of English, 1-26. Amsterdam: John Benjamins.

Tanaka, Noriko, Helen Spencer-Oatey and Ellen Craig. 2008. Apologies in Japanese and English. In H. Spencer-Oatey (ed.), Culturally Speaking: Culture, Communication and Politeness Theory, 73-94. London Continuum.

Thomas, Jenny. 1995. Meaning in Interaction: An Introduction to Pragmatics. London: Longman.

Trosborg, Anna. 1987. Apology strategies in natives/non-natives. Journal of Pragmatics 11: 147-167.

Trosborg, Anna. 1995. Interlanguage Pragmatics. Requests, Complaints and Apologies. Berlin: Mouton de Gruyter.

\section{NOTES}

1. Mattson Bean and Johnstone (1994) examine two other 'apology' forms, i.e. excuse me/'scuse me and I beg your pardon/pardon (me), but (I'm) sorry remains their main object of study.

2. Note, however, that Trosborg (1987: 151) recognises that her category 'request for forgiveness' is oversimplified.

3. This is perfectly summarised by Papafragou (2018: 167) when she highlights the traditional theoretical opposition between "linguistically encoded (semantic) and contextually derived (pragmatic) aspects of communicated meaning". 
4. The same kind of criticism was developed in Thomas's (1995) textbook Meaning in Interaction which tries to make up for these shortcomings by according a central place to the roles of both speaker and hearer in the construction of meaning". Thomas (1995: 22) claims that "meaning is not something which is inherent in the words alone, nor is it produced by the speaker alone, nor by the hearer alone". Rather, 'making meaning' is seen as "a dynamic process".

5. For example, Douay (2001: 89) salutes Lambrecht's effort to introduce "a syntax for conversation" (1994) and Schlegloff's call for a grammar "retheorized for interaction" (1996: 52-133).

6. The word is ours and we use it to clarify Douay and Roulland's (2014) concept of replication.

7. This distinction is crucial for a shift of focus from an interpersonal relation to an interlocutive relation (Douay, 2001: 83).

8. We shall see that this type of anticipation can serve to manipulate hearers by forcing upon them a purported common interpretation. See example (7) in Section 5, for instance.

9. This, in turn, could explain the much higher frequency rate of sorry-based apologies reported in several previous studies. In Holmes's (1990 : 172) and Aijmer's (1996: 86) studies, respectively, $79.3 \%$ and $83.7 \%$ of the apologies studied were variants of sorry. In Deutschmann (2003:51), the discrepancy between excuse- and sorry-based apologies is also quite obvious : out of a total of 3072 "explicit" apologies, 59.2\% contained the word sorry while only $10.4 \%$ contained excuse.

10. In other contexts, the speaker may choose to highlight the antagonistic relationships existing between $\alpha$ and $\beta$ but what remains is the call for hearer participation (cf. example (5)).

11. Although we describe excuse me and (I'm) sorry in terms of a challenging vs non-challenging IR rather than in terms of degrees of politeness, this analysis seems to be consistent with Aijmer's (2018) study on attention-getters in adolescents' speech. Following Leech (2014), Aijmer (2018: 191) notes that excuse me is often used with ironic undertones and that "the speaker says something which is interpreted as 'polite' on the surface but is 'more deeply' interpreted as impolite".

12. For lack of space, we had to limit ourselves to just a few specific situations but the contrast between excuse me and (I'm) sorry is obvious in many others, as we intend to show in further research.

13. Interestingly, sorry about that is five times as frequent as sorry about this in Deutschmann's corpus. According to the author, "that seems to function as a device to dissociate the offender from the offence" (2003: 56).

14. Thus, the fact that American speakers tend to use excuse me in post-bumping situations, contrary to other speakers of English, may be revealing of different politeness conventions. In particular, because it replicates a polarised IR, a C1-marker of this type could, in particular, be interpreted by the hearer as a sign that the speaker is still trying to connect with her and establish good interpersonal rapport following the disruptive event. It might well be that British politeness, by relying on a C2-marker in the same situation, normally hinges on an attempt to communicate the idea that offenders take full responsibility and admit to the aggravating nature of the event. 


\section{ABSTRACTS}

Building on the Theory of Interlocutive Relation, we hypothesise that the semantic and pragmatic meaning of excuse me and (I'm) sorry, which are not fundamentally forms of apology, derives from the fact that they establish two different kinds of Interlocutive Relations, guiding towards possible interpretations of a disruptive event. We analyse excuse me as a duophonic marker', i.e. a form imposing disharmony between an emission and a reception profile. This can be taken as a way to request hearer cooperation for the sake of politeness, in an attempt to remedy a breach of etiquette or, rather to the contrary, as a way to exacerbate the conflicting nature of a situation in non-apologetic contexts. On the other hand, we assume that (I'm) sorry is a 'monophonic form' meant to restore interlocutive harmony between the two profiles. Hearer cooperation is then taken for granted and downplays conflict in apologetic and non-apologetic situations.

Dans le cadre de la Théorie de la Relation Interlocutive, nous proposons que l'interprétation sémantique et pragmatique de excuse me et (I'm) sorry, qui ne sont pas, par essence, des marqueurs d'excuse, s'effectue en fonction de deux types de relation interlocutive différents qui conduisent à plusieurs interprétations possibles d'un événement perturbateur. Excuse me est considéré comme marqueur duophonique, c'est-à-dire comme une forme qui impose un désaccord entre un pôle émetteur et un pôle récepteur. On pourra y voir une demande de coopération de l'allocutaire par politesse, pour tenter de réparer un manquement à l'étiquette, ou, bien au contraire, un moyen d'accentuer la nature conflictuelle d'une situation dans un contexte autre qu'un contexte d'excuse. A l'inverse, nous faisons l'hypothèse que (I'm) sorry est une forme monophonique qui s'emploie pour rétablir l'harmonie interlocutive entre les deux pôles. Avec ce marqueur, la coopération de l'allocutaire est considérée comme acquise, ce qui a pour effet de minimiser le conflit dans des situations d'excuse ou autres.

\section{INDEX}

Mots-clés: duophonie, (dés)accord, relation interlocutive, monophonie

Keywords: duophony, (dis)harmony, interlocutive relation, monophony

\section{AUTHORS}

\section{HÉLÈNE MARGERIE}

Université Bordeaux Montaigne, CLIMAS (EA 4196)

Domaine universitaire, Esplanade des Antilles, 33607 Pessac, France

Contact: helene.margerie@u-bordeaux-montaigne.fr

\section{PHILIPPE MULLER}

Université Bordeaux Montaigne, CLIMAS (EA 4196)

Domaine universitaire, Esplanade des Antilles, 33607 Pessac, France

Contact: philippe.muller@u-bordeaux-montaigne.fr 